\title{
Effect of solution concentrations on the morphology of nylon6/66 nanofibrous yarns by blown bubble-spinning
}

\author{
Hao DOU ${ }^{1,3}$, Hong-Yan LIU ${ }^{2}$, \\ Ping WANG ${ }^{1,3}$, Ji-Huan HE ${ }^{1,3}$
}

\author{
${ }^{1}$ Nantong Textile Institute, Soochow University, Nantong, China \\ ${ }^{2}$ School of Fashion, Zhongyuan University of Technology, Zhengzhou 450007, China \\ ${ }^{3}$ National Engineering Laboratory for Modern Silk, College of Textile and Engineering, Soochow University, People's \\ Republic of China \\ e-mail: hejihuan@suda.edu.cn
}

\begin{abstract}
In this paper, a novel method called blown bubble-spinning was employed to produce nanofibers. Compared with the traditional technologies, such as melt blowing and electrospinning, hot airflow is used in blown bubble-electrospinning to overcome the surface tension of the polymer bubbles and to pull multiple jets from the broken bubble into nano scale ones which are solidified to nanofibers after solvent evaporation, the technology requires no electrostatic force. The effect of Nylon6/66 polymer concentration on the morphology of nanofibers is investigated. The results indicate that nanofibers without beads were successfully fabricated under this one-step process and spontaneously aggregated to form superfine fiber assemblies. Besides, average diameters of both fiber assemblies and inner nanofibers increased with polymer concentrations, ranging from 6 micrometers to 34 micrometers and $180 \mathrm{~nm}$ to $524 \mathrm{~nm}$, respectively. This study provides a promising approach to directly generate fiber assemblies composed of nanofibers, which may show great potential in the future applications.
\end{abstract}

Keywords: Blown bubble-spinning, nanofibers, yarns, Nylon.

\section{INTRODUCTION}

Recently, fibers with nanoscale diameters have attracted much attention since they own unique features, such as large specific surface area, very small pore size with high porosity and superior mechanical properties [13]. Also, methods for directly producing nanofibers are rapidly developed for meeting the various requirements and applications [4-7]. Among these approaches electrospinning shows its great potential on fabrication of nanofibers as a simple and effective way [요밍. However, low throughput from electrospinning limits its large-scale development in industry which prompts new techniques to overcome this problem with some modifications [11-14]. On the other hand, melt-blowing is well-known as an industrial method for the high production of nonwoven fibers. Only when very small orifices are employed can we obtain nanofibers rather than micrometer fibers [14-18].

The research object suffering from elongation is changed in the form of bubble instead of traditional solution or melt from a needle or an orifice die [19-20]. Bubble electrospinning is a good example which has shown excellent capability to fabricate nanofibers for mass production. The surface tension of a polymer bubble geometrically depends upon its size and the pressure difference, which is illustrated in the derived Young-Laplace equation [21]:

$$
\sigma=\frac{1}{4} r \Delta p
$$

Thus, fiber fabrication process could be achieved by overcoming the tiny surface tension from many ruptured bubbles with all kinds of forces. 
In this paper, we describe a blown bubble-spinning method [22,23] to produce nanofibers of which drag force are replaced by high-speed streams of hot airflow. And different concentrations of nylon6/66 solutions were prepared to investigate the feasibility of blown bubble-spinning technology in manufacturing nanofibers.

\section{EXPERIMENTAL}

\subsection{Preparation of Nylon 6/66 spinning solutions}

Nylon6/66 $\left(\mathrm{C}_{18} \mathrm{H}_{37} \mathrm{~N}_{3} \mathrm{O}_{5}\right.$, Mw375kDa) was purchased from Sigma, USA. The spinning solutions were respectively prepared by dissolving nylon6/66 at the concentration of $8 \%, 11 \%$ and $14 \%$ in formic acid $(88 \% \mathrm{v} / \mathrm{v}$, Sinopharm Chemical Reagent Co., Ltd, China) under slight stirring for 4 hours.

\subsection{The process of blown bubble-spinning}

The experimental set-up of the blown bubble-spinning was indicated in Figure 1. Briefly speaking, compressed gas is released inside the spinning solution to generate one bubble. The single bubble is rising along the tube and formed on the free surface of the orifice. At the same time, the blowing hot air in the form of two streams that shape a V-slot pulls the droplets of the bubble upwards rapidly and continuously. Then superfine fibers are obtained on the collector. This process is repeated until the polymer bubble in the tank could not be generated. The diameter of orifice is 5.5 millimeter and the die-to-collector distance is constant as $15 \mathrm{~cm}$. Temperature and airflow rate used in this experiment are $180^{\circ} \mathrm{C}$ and $500 \mathrm{~L} / \mathrm{min}$, respectively.

\subsection{Rheological Analysis}

Rheological studies were run on a Rheometer (TA Instruments, AR2000, America) with a 40 mm cone plate (Ti, 40/2 ${ }^{\circ}$. The normal force applied on the sample during lowering of the top plate was limited to $0.1 \mathrm{~N}$. The shear rate was linearly increased from 0.1 to $50001 / \mathrm{s}$ at $25^{\circ} \mathrm{C}$.

\subsection{Scanning Electron Microscopy}

The morphology of electrospun SF nanofibers was observed using an SEM (Hitachi S-4800,Japan) at $20^{\circ} \mathrm{C}$, $60 \mathrm{RH}$. Samples were mounted on a copper plate and sputter-coated with gold layer 20-30 nm thick prior to imaging. The diameters of the fibers were measured from randomly collected SEM images using the Image J software and expressed as mean \pm standard deviation (SD).

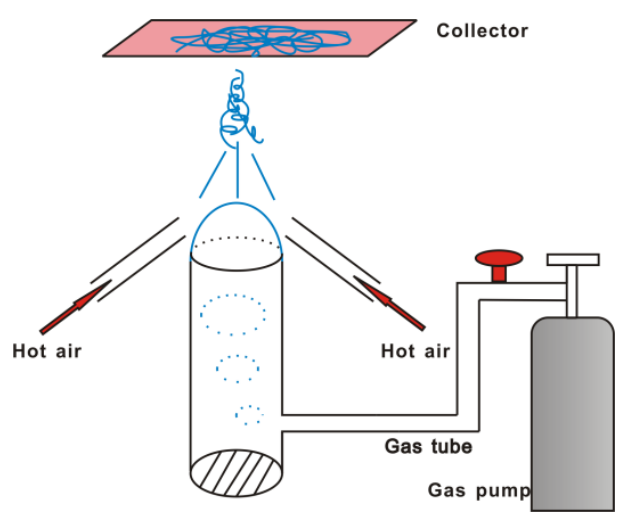

Figure 1: The schematic of the experimental set-up. 


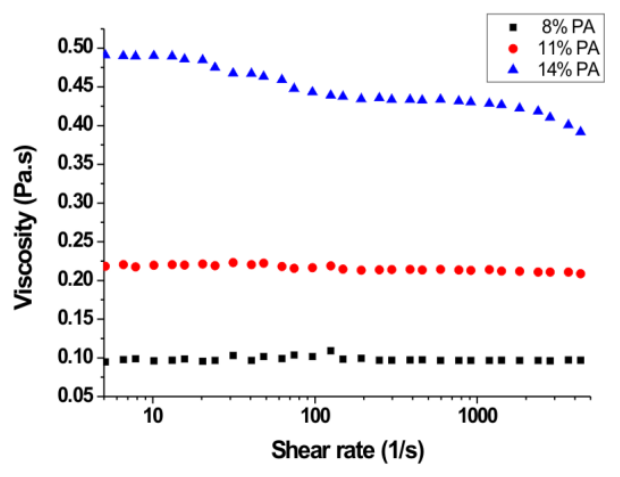

Figure 2: Relationship between the shear viscosity and shear rate of the PA6/66/FA solutions with different polymer concentrations.

\section{RESULTS}

\subsection{Rheological Property of PA6/66/FA solutions}

In all blown spinning methods, aerodynamic drag from airflow fields plays a significant role in the formation of fibers. Figure 3 provides the information about morphologies of superfine fibers under different airflow directions. When the direction of airflow is vertical to the path of polymer bubble, the fiber attenuation occurred in a complex situation with the time and space, which leads to a random array structure similar to that of electrospun nanofibers (Figure 3 left). However, the direction consistency between airflow and bubble ejection caused fiber mass to be concentrated in fiber bundles rather than distributed over a large area. It can be concluded that the centerline air velocities from the dual airflow is the main cause (Figure 3 right). Solution viscosity is viewed as one of the most important variables in determining the fiber diameter and morphology [17, 24-25]. Figure 2 illustrated the relationship between the shear viscosity and shear rate of PA/FA spinning solutions with different concentrations. $8 \%$ and $11 \%$ solutions exhibited as a shearindependent Newtonian flow while $14 \%$ one showed a slight shear thinning behavior. This is because an increased amount of polymer leads to complex entanglement of molecular chains which restricts the mobility. Nevertheless, the viscosity of solutions was dependent on the concentration i.e. the viscosity rose with an increase of the solution concentration.
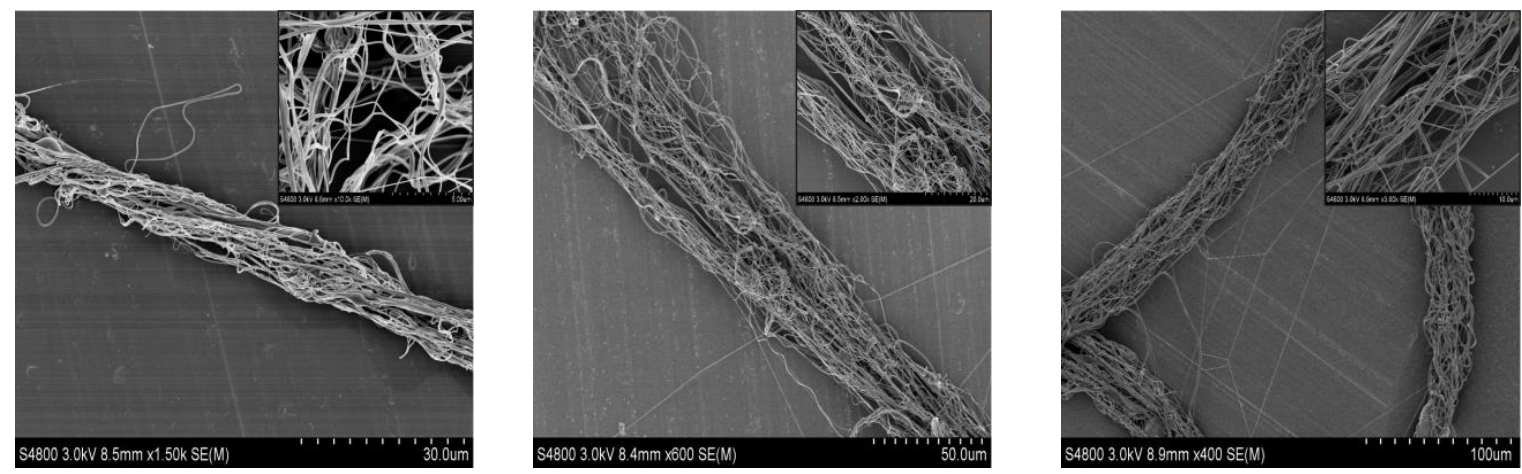

Figure 3: SEM images of the blown bubble-spun superfine fiber assemblies and inner nanofibers (top right) from solutions with different PA6/66 concentrations, (left): $8 \%$, (middle): $11 \%$, and (right): $14 \%$ 


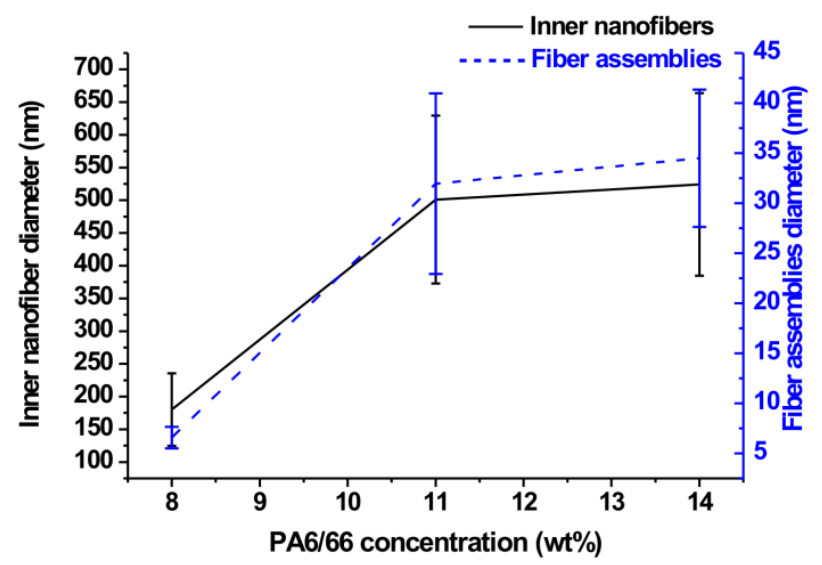

Figure 4: Average diameter of the superfine fiber assemblies and inner nanofibers with different PA6/66 concentrations

\subsection{Fiber morphology}

As expected, fiber morphology is associated with solution concentrations. The morphologies of outcomes fabricated from different PA6/66 concentrations were observed in Figure 3. Instead of randomly oriented nanofibers as usual (e.g. electrospinning technology), we also obtain fiber assemblies. The reason for this phenomenon may be that aerodynamic interactions result in gradual split of the polymer bubble and its fragments, and then rapidly get them together again. According to Figure 4, further analysis reveals that the average diameter of fiber assemblies and inner nanofibers becomes thicker with the concentration of polymer solutions. On the other side, beaded fibers or shots are not clearly found when employing solutions of low concentration and viscosity. However these could typically be observed in electrospinning although the average diameter of fiber assemblies exceeds micrometer scale.

\section{CONCLUSIONS}

The PA6/66 superfine fiber assemblies formed from numerous nanofibers were successfully fabricated by a novel method called blown bubble-spinning. By adjusting the concentrations of spinning solutions from $8 \%$ to $14 \%$, average diameters of both fiber assemblies and inner naofibers are correspondingly varied from $6.57 \pm 1.08$ um to $34.49 \pm 6.87 \mathrm{um}$ and from $180.28 \pm 55.43 \mathrm{~nm}$ to $524.33 \pm 139.5 \mathrm{~nm}$. In addition, blowing hot air is applied on the broken polymer bubble rather than viscous melt, which reduces the gap between blown spinning and electrospinning technology in terms of the ability to produce nanoscale fibers. And the obtained fibers with special structure would broaden their applications to meet the demands in various fields.

\section{ACKNOWLEDGEMENT}

The work is supported by Priority Academic Program Development of Jiangsu Higher Education Institutions (PAPD), National Natural Science Foundation of China under grant No.11372205 and Project for Six Kinds of Top Talents in Jiangsu Province under grant No.ZBZZ-035, Science \& Technology Pillar Program of Jiangsu Province under grant No.BE2013072 , Jiangsu Province Key Laboratory No.KJS1314 and Jiangsu Planned Projects for Postdoctoral Research Funds1401076B.

\section{BIBLIOGRAPHY}

[1] NANDANA, B., SUBHAS, C. K., "Electrospinning: A Fascinating Fiber Fabrication Technique", Biotechnology Advances, v.28, n.3, pp. 325-347, 2010.

[2] LI, D., XIA, Y. N., "Elecreospinning of Nanofibers: Reinventing the Wheel"? Adanced Materials, v.16, n.14, pp. 1151-1170, 2004.

[3] AGARWAL, S., et al., "Functional Materials by Electrospinning of Polymers", Progress in Polymer Science, v.38, n.6, pp. 963-991, 2013.

[4] TONG, H. W., WANG, M., "A Novel Technique for the Fabrication of 3D Nanofibrous Scaffolds Using Simultaneous Positive Voltage Electrospinning and Negative Voltage Electrospinning”, Materials Letters, v.94, n.1, pp. 116-120, 2013. 
[5] WANG, X., et al., “An Improved Tip-less Electrospinning with Strip-distributed Solution Delivery for Massive Production of Uniform Polymer Nanofibers”, Materials Letters, v.99, n.15, pp. 21-23, 2013.

[6] SINHA-RAY, S. et al., "Supersonic Nanoblowing: A New Ultra-Stiff Phase of Nylon 6 in 20-50 nm Confinement”, Journal of Materials Chemistry C, v.1, n.21, pp. 3491-3498, 2013.

[7] XU, L., SI, N., Lee, E.W.M., et al., “ A multi-phase flow model for electrospinning process”, Thermal Science, v. 17, n. 5, pp. 1299-1304, 2013

[8]LI, H.B., KONG,H.Y., et al., "Particle-like beads and daughter jet cascades in electrospinning", Thermal Science, V. 17, n. 5, pp. 1421-1424, 2013

[9] CHEN, R.X., ZHANF,L., et al., "Mechanism of nanofiber crimp”, Thermal Science, v. 17, n. 5, pp. 14731477,2013

[10] PANG, J., KONG, H.Y., et al., "PVA-based nanographene film by electrospinning”, Thermal Science, v. 17, n. 5, pp. 1449-1452, 2013

[11] DALTON, P. D., et al., "Electrospinning and Additive Manufacturing: Converging Technologies", Biomaterials Science, v.1, n.2, pp.171-185, 2013.

[12] LUO, C. J., et al., "Electrospinning versus Fibre Production Methods: from Specifics to Technological Convergence", Chemical Society Reviews, v.41, n.13, pp.4 708-4735, 2012.

[13] PERSANO, L., et al., "Industrial Upscaling of Electrospinning and Applications of Polymer Nanofibers: A Review", Macromolecular Materils and Engineering, v.298, n.5, pp. 504-520, 2013.

[14] ZUO, F., et al., "Nanofibers from Melt Blown Fiber-in-Fiber Polymer Blends", ACS Macro Lett., v.2, n.4, pp.301-305, 2013.

[15] NAYAK, R., et al., Fabrication and Characterization of Polypropylene Nanofibres by Meltblowing Process Using Different Fluids, Journal of Materials Sciences, v.48, n.1, pp, 273-281, 2013.

[16] UPPAL, R., et al., "Meltblown Nanofiber Media for Enhanced Quality Factor", Fibers and Polymers, v.14, n.4, pp.660-668, 2013.

[17] ELLISON, C. J., et al., "Melt Blown Nanofibers: Fiber Diameter Distributions and Onset of Fiber Breakup”, Polymer, v.48, n.11, pp. 3306-3316, 2007.

[18] HASSAN, M. A., et al., "Fabrication of Nanofiber Meltblown Membranes and Their Filtration Properties", Journal of Membrane Science, v. 427, pp. 336-344, 2013.

[19] CHEN, R.X., ZHANF,L., et al., Mechanism of nanofiber crimp, Thermal Science, V. 17, n. 5, pp. 14731477,2013

[20] YANG, R. R., et al., "Bubble-electrospinning for Fabricating Nanofibers", Polymer, v.50, n.24, pp. 5846-5850, 2009.

[21] LIU,F.J., DOU, H. “A modified Young-Laplace equation for the bubble electrospinning considering the effect of humidity", Thermal Science, V. 17, n. 5, pp. 629-630, 2013

[22] DOU, H., LIU, H.Y., et al. "A belt-like superfine film fabricated by bubble-electrospinning”, Thermal Science, V. 17, n. 5, pp. 1508-1510, 2013

[23]CHO, H. J., et al., "Molecular Weight Distribution and Solution Properties of Silk Fibroins with Different Dissolution Conditions", International Journal of Biological Macromolecules, v.51, n.3, pp. 336-341, 2012.

[24] HEIKKILÄ, P., HARLIN, A., "Parameter Study of Electrospinning of Polyamide-6", European Polymer Journal, v.44, n.10, pp. 3067-3079, 2008.

[25] TSOU, S. Y., et al., "Studies on the Electrospun Nylon 6 Nanofibers from Polyelectrolyte Solutions: 1. Effects of Solution Concentration and Temperature", Polymer, v.52, n.14, pp. 3127-3136, 2011. 